\title{
Stress Coping and Issues among Evacuees Four Years after the Nuclear Disaster in Fukushima: An Interview Study
}

\author{
Toshiko Tomisawa1, Yuki Kimura², Maiko Kitajima1, Kasumi Mikami1 \\ ${ }^{1}$ Department of Nursing Science, Hirosaki University Graduate School of Health Sciences, Hirosaki, Japan \\ ${ }^{2}$ Tokai University Medical Hospital, Kanagawa, Japan \\ Email:tmtott@hirosaki-u.ac.jp, yukikimura3@yahoo.co.jp, kitajima@hirosaki-u.ac.jp, k-mikami@hirosaki-u.ac.jp
}

How to cite this paper: Tomisawa, T., Kimura, Y., Kitajima, M. and Mikami, K. (2018) Stress Coping and Issues among Evacuees Four Years after the Nuclear Disaster in Fukushima: An Interview Study. Open Journal of Nursing, 8, 210-220. https://doi.org/10.4236/ojn.2018.83018

Received: February 24, 2018

Accepted: March 25, 2018

Published: March 28, 2018

Copyright $\odot 2018$ by authors and Scientific Research Publishing Inc. This work is licensed under the Creative Commons Attribution International License (CC BY 4.0).

http://creativecommons.org/licenses/by/4.0/

\begin{abstract}
Purpose: The purpose of the present study was to clarify issues related to the evacuation process, including stress coping, psychological conditions, and health problems, through interviews with long-term evacuees 4 years after the Great East Japan earthquake and nuclear disaster. Methods: Group interviews focusing on stress and health conditions were conducted with eight older adults at a meeting space in Y city in Fukushima Prefecture, Japan, in May 2015. Two months later, based on the results of the first group interview, four (two men, two women, age range, 60 - 70 years) of those eight individuals participated in 60-min individual semi-structured interviews and were assessed according to the Tri-axial Coping Scale revised for the elderly. The interviewees were asked about their anxiety and hardships, escape routes, and other points of importance. Results: Stress coping scores were higher for males than for females, especially that for "Catharsis". The "Giving up" score was higher among these participants than the general population. In the interviews, the participants described how evacuees from "Q" area were experiencing high levels of stress because of problems communicating with their neighborhoods and receiving compensation from the government and Tokyo Electric Power Company. Conclusion: Evacuees experienced hardships immediately after the earthquake, including issues related to compensation from the government and communication with their neighborhoods. Men showed higher scores for "Avoidance-like thinking" and "Giving up" than for other factors related to stress coping, suggesting that they might not use "Catharsis" as a means of coping with stress. The results also suggested that men experienced repeatedly that alone, they made little headway or could not do something. The present study suggests the importance of providing support to long-term evacuees so that original residents can better understand their situation.
\end{abstract}




\section{Keywords}

Stress Coping, Nuclear Disaster, Earthquake, Evacuation

\section{Introduction}

Nearly 7 years have passed since the Great East Japan earthquake, which occurred on March 11, 2011, generating a catastrophic tsunami [1] that killed 15,885 people and injured another 6148 [2]. The Fukushima Daiichi nuclear power plant in Fukushima Prefecture was also damaged by a subsequent hydrogen explosion. As of January 2016, there were still over 100,000 evacuees remaining from the original 164,865 evacuees in Fukushima [3]. In "Q" area around the nuclear power plants, which was contaminated by radioactive material, all 21,434 residents had to evacuate to other places in Fukushima or outside of Fukushima altogether. Some of these evacuees remain in temporary housing and others still live in rental housing from the government [3] [4]. In addition, about 1000 companies in "Q" area were affected by the disaster [5]. The suicide rate increased for several years after the Great Hanshin earthquake in 1995 [6]; therefore, it is necessary to examine whether such disasters are associated with high-risk problems for isolated evacuees or those with mental health problems, because such persons find it difficult to maintain or build good relationships. In addition, few studies have examined health conditions among evacuees more than 4 years after the earthquake and nuclear power plant disaster.

Therefore, the purpose of the present study was to clarify issues related to the evacuation process, including stress coping, psychological conditions, and health problems, through interviews with long-term evacuees 4 years after the Great East Japan earthquake and nuclear disaster. The formatter will need to create these components, incorporating the applicable criteria that follow.

\section{Methods}

\subsection{Study Design}

This was a qualitative phenomenological study.

\subsection{Participants}

The study participants were four residents (two men, two women; age range, 60 - 70 years) of an evacuation area in Fukushima Prefecture, Japan. Their home town were "Q" area where all resident have to evacuate around Fukushima nuclear power plant.

\subsection{Ethical Considerations}

This study was approved by the Institutional Review Board at the University of Hirosaki University Graduate School of Health Sciences. The purpose and pro- 
cedures of the study were explained to all participants and questions were invited. All participants were told that they could withdraw from the study at any time. Informed consent was obtained from all participants in writing.

\subsection{Data Collections}

Eight older adults participated in a group interview about stress and health conditions at $\mathrm{Y}$ city in Fukushima in May 2015. Two months later, for relationship-building based on the results of the first group interview, four (two men, two women, age range, 60 - 70 years) of those eight individuals who agreed to interview participated in 60-min individual semi-structured interviews about their anxiety and hardships, escape routes, and other points of importance, and were assessed according to the Tri-axial Coping Scale revised for the elderly (TAC-24E), which measures the ability to cope with sources of frustration in daily life. The TAC-24E consists of 12 items and classifies coping mechanisms into the following four factors: "Catharsis", "Plan drafting", "Avoidance-like thinking", and "Giving up" [7] [8]. In the questionnaire, the participants were asked "When you face obstacles, how do you think or cope with your hardships?" The answers were rated on a five-point self-reporting scale, ranging from 1 ("I have never done [thought of] it") to 5 ("I have always done [thought of] it"), and total scores were calculated according to the subscales.

\subsection{Analytic Procedures}

We assessed trends in stress coping according to the TAC-24E scores, which were compared with average scores for each generation. We analyzed the interview transcripts using thematic analysis in which transcript data was combined according to items and categorized by similar context. To assure reliability and validity, we checked the analyzed content with a supervisor who had joined in on the interviews to confirm that it was consistent with each interviewee.

\section{Results}

\subsection{Characteristics of the Participants}

The study participants were two males and two females (mean age, 67 years). They all ran their own businesses before the Great East Earthquake.

\subsection{Results of TAC-2E}

Table 1 shows result of TAC-2E. The numbers in parentheses are the mean stress coping scores for middle-aged people in the general population. Stress coping scores are higher for men than for women, especially that for "catharsis".

The "Giving up" score was slightly higher among these participants than the general population.

\subsection{Results of Interview}

The problems, thoughts, and feelings of the four participants are shown in Figures $1-4$, respectively. In the figures, the participants' problems and current 
Table 1. TAC-2E in participants.

\begin{tabular}{ccccccc}
\hline Participant & Sex & Age & Catharsis & Plan drafting & $\begin{array}{c}\text { Avoidance-like } \\
\text { thinking }\end{array}$ & Giving up \\
\hline A & female & $70 \mathrm{~s}$ & $11(9.8)$ & $13(11.6)$ & $8(12.2)$ & $4(9.8)$ \\
B & male & $70 \mathrm{~s}$ & $3(7.3)$ & $5(10.0)$ & $11(11.1)$ & $9(8.3)$ \\
C & female & $60 \mathrm{~s}$ & $8(10.1)$ & $13(11.2)$ & $11(11.1)$ & $12(7.8)$ \\
D & male & $60 \mathrm{~s}$ & $3(7.0)$ & $11(9.1)$ & $11(10.9)$ & $7(6.6)$ \\
\hline
\end{tabular}

hardships are shown in clouds, keywords are shown in squares, and important points are shown in circles.

\subsubsection{Participant A, Female in Her 70s}

"A" evacuated to a junior high school in E town right after the earthquake, and then stayed at the home of an acquaintance for one night. She then stayed at $\mathrm{X}$ school in F city for two nights. Since it started to accept evacuees, she moved to a gym in $\mathrm{Y}$ city and stayed there for 44 days. She moved to somewhere in $\mathrm{G}$ town and stayed at other place in $G$ town for 2 months. She then stayed calmly at $Y$ while occasionally looking for old documents at her disaster-stricken home.

At the beginning of the disaster, the hardest things for her were being given meals twice a day at X school in F city, not being able to wash her hands because there was no water, feeling cold because she did not have enough clothes, having to stay with unfamiliar people at the gym, not being able to meet her younger sister and son, having the windshield of her rental car broken by a rock from an oncoming car, and not being able to buy any gas (Figure 1).

She also talked about difficult things such as having compensation claims rejected despite the fact that her disaster-stricken home and safe had been broken into by a thief, as well as by wild animals. After evacuating, she had a tooth removed, but was annoyed when the dentist told her that she could not have a new tooth because evacuees do not have much money. She experienced numerous annoying problems such as not receiving any compensation from Tokyo Electric Power Company (TEPCO) and not being able to pay rent where she lived because she was not able to contact the landlord. In addition, she had insomnia and gastric ulcers because she was actively running her business before evacuating; this also explains why it was difficult for her to have nothing to do other than watching TV. You are now ready to style your paper.

\subsubsection{Participant $B$, Male in His 70s}

"B" had stayed at home during the earthquake. After things started to calm down, he took his grandchild to preschool. Then, he suddenly heard that a tsunami would hit, so he evacuated his family to higher ground. They came back home to eat dinner after a while. However, there was an explosion at the nuclear power plant the next morning, so they evacuated F town for 3 days. Next, they evacuated to I town. B has two daughters. One daughter recommended evacuating J city, so they moved and stayed there for about 20 days. The other daughter 


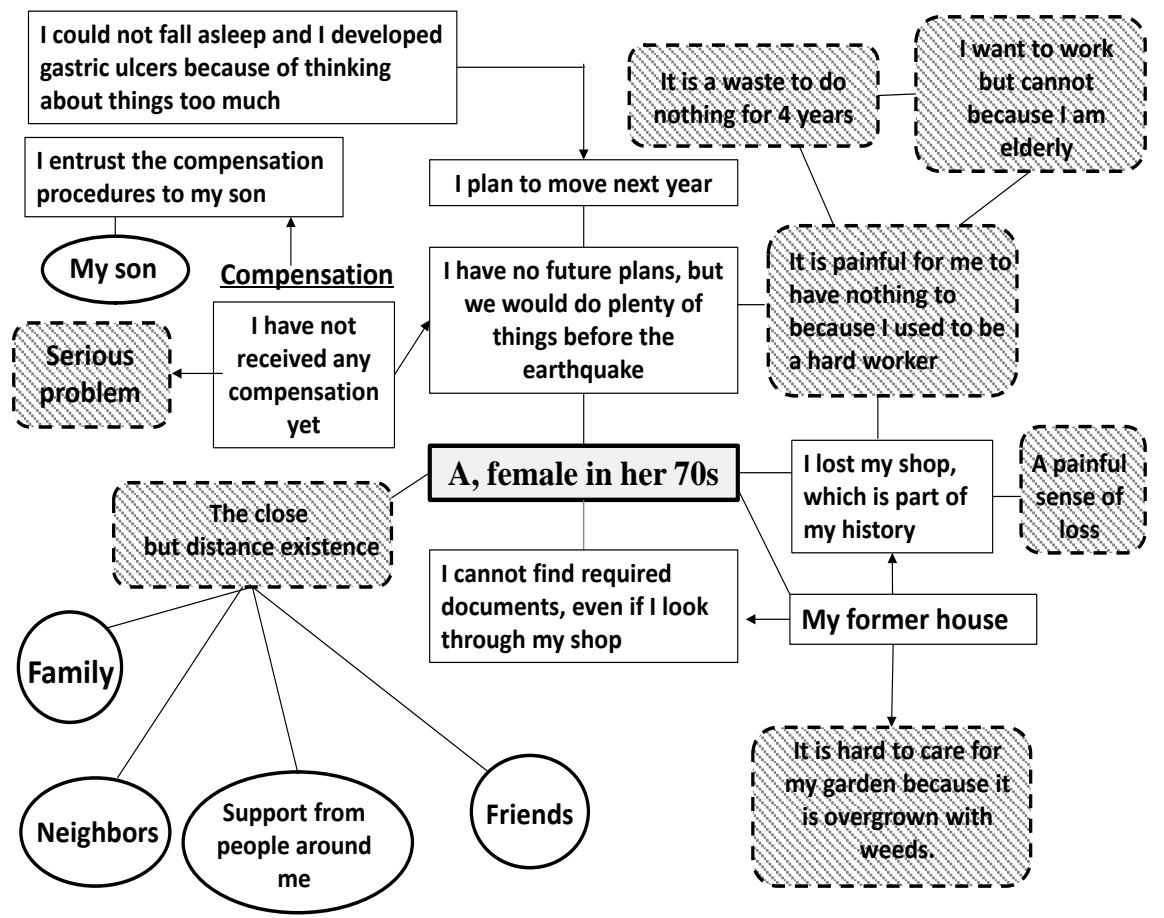

Figure 1. Story on Participant A. ${ }^{\star}$ Circle with solid line presents positive thing on participant. Square presents stories participants described. Shaded square with dot line presents participant's emotion.

worked at city hall in $\mathrm{Z}$ town and then relocated to $\mathrm{Y}$ city, so she recommended that he move there with her. They stayed in a hotel for 3 months, and then moved to an apartment in $\mathrm{Y}$ city. He ended up staying in temporary housing in $\mathrm{Y}$ city that was provided by the government because there were limited options. He said that he and his family members had to stay in their car at the beginning of the evacuation, and that they did not have enough money or clothing because they thought they would be able to come back after 2 or 3 days. Therefore, they felt embarrassed at that time. After moving to $\mathrm{Y}$ city, they felt very lonely because they were unfamiliar with the environment and neighborhood. He also had difficulty taking care of his baby grandchild, who often cried in the apartment, and he felt anxious living there because he had little communication with his neighbors for 1 year. Therefore, he set up a self-help group to catch up with people from $\mathrm{Q}$ town.

At 5 years from disaster, he worried about increasing medical expenses resulting from discontinued compensation from TEPCO, and hoped to stay in his own home for a long time, not continue to live in temporary housing (Figure 2). He was also worried that receiving too much compensation would evoke envy in his neighborhood. Before the disaster, he often rode his bike to work, but now he was getting less exercise, and thus developed pain in his knees and lower back. He also had continuous anxiety about the effects of radiation on his child and grandchild, as well as about the government restarting several nuclear power plants. 


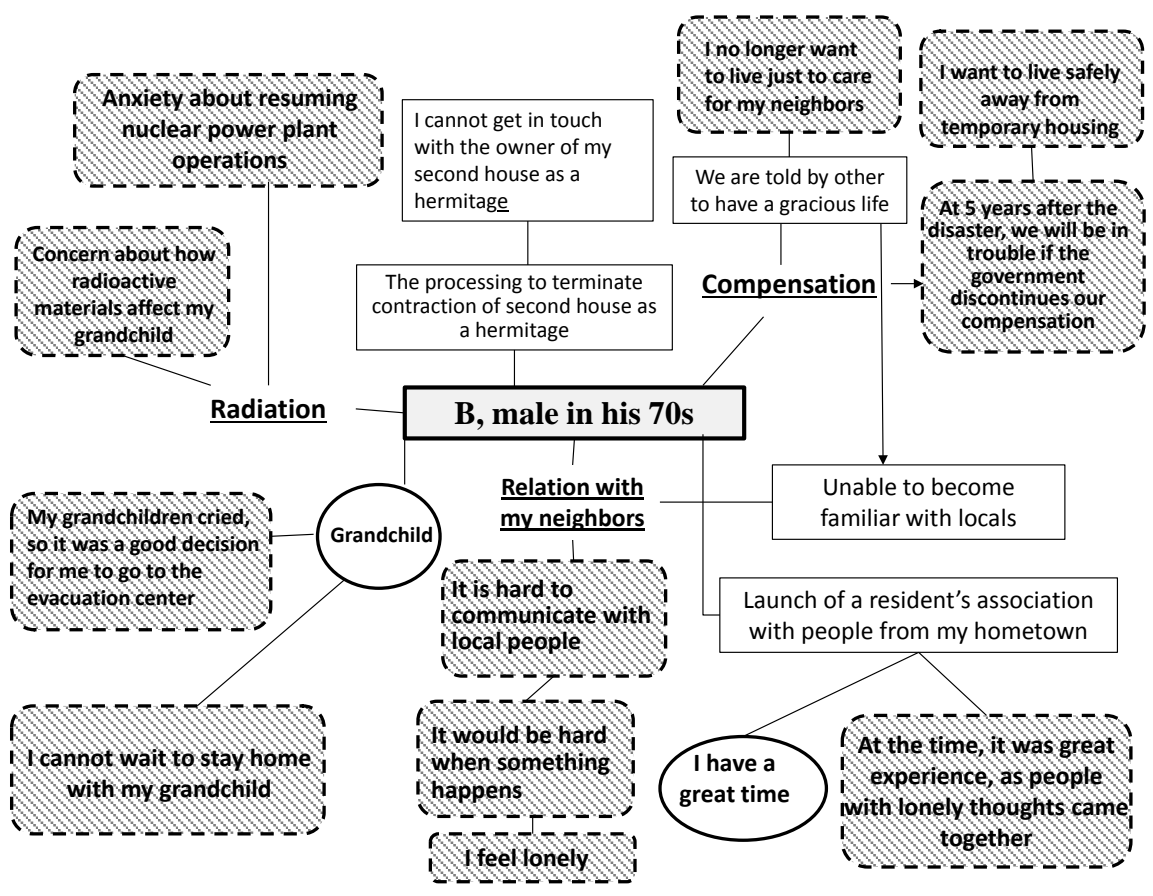

Figure 2. Story on Participant B. ${ }^{\star}$ Circle with solid line presents positive thing on participant. Square presents stories participants described. Shaded square with dot line presents participant's emotion.

\subsubsection{Participant C, Female in Her 60s}

When the earthquake occurred, $\mathrm{C}$ had just opened her farmer's market. She evacuated to higher ground, and then went to her son's apartment. She got back home later that night. She cleaned up her messy room the next morning, but then her son asked her to evacuate to a safer place, so they evacuated with the family to L town for 9 days. Next, they moved to M gym for 3 days. The living spaces for the family were narrow, and they felt a chill at night, so they could not sleep well.

After moving to another evacuation center, she felt that she did not want to interfere with the neighborhood (Figure 3). Other people did not understand them, even though they explained that were suffering several hardships that could not be solved by money. Evacuee was considered a representative of compensations. That is, evacuees were widely regarded as being well looked after by the government. She complained that the neighborhood was interfering with her livelihood and compensation, among other things.

\subsubsection{Participant D, Male in His 60s}

"D" and his wife evacuated F city at the beginning of the disaster, and then moved to the home of one of his wife's relatives for a few days. They then moved to their daughter's home in $\mathrm{O}$ city. Next, they moved to a community center in $\mathrm{X}$ town, but were told that they could not stay, so they moved to $\mathrm{P}$ town. Next, they went to $\mathrm{Q}$ city as they relied on the other daughter. They stayed at a hotel for 1 week and rented an apartment for 1 month. They then moved to a resort hotel in Q city and lived there for several months. Finally, they moved to Y city. 


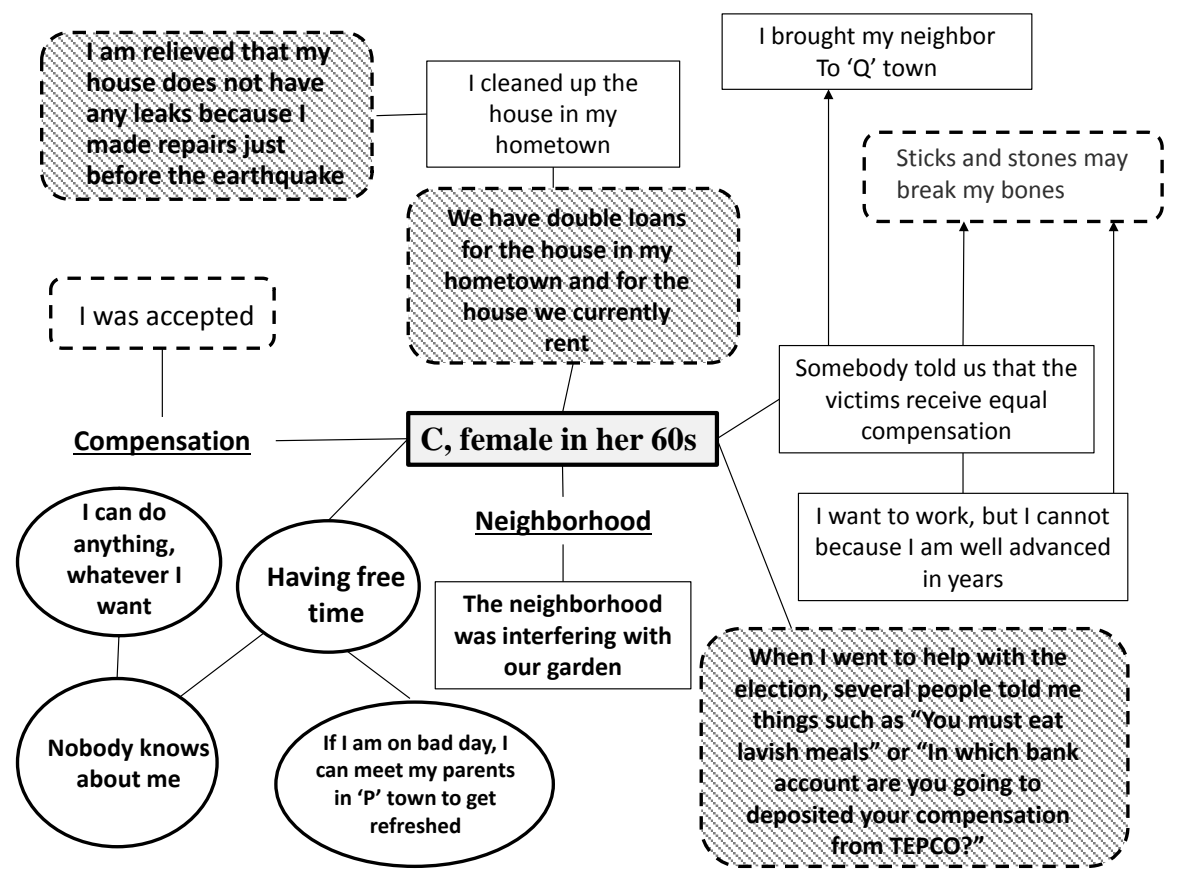

Figure 3. Story on Participant C. ${ }^{\star}$ Circle with solid line presents positive thing on participant. Square presents stories participants described. Shaded square with dot line presents participant's emotion.

They currently live in their second rental home. They evacuated with nothing right after earthquake, so they have gone through many hardships.

" $D$ " described that it was hard to maintain their space using cardboard barriers at the evacuation center and that they felt cold because as their warm clothes had been contaminated by radioactive material, they only had thin clothes to wear.

They were used to clearing away snow every day, so they became exhausted and did not feel well. They also felt stress from driving in the snow (Figure 4). "D" was also dissatisfied with compensation. They had to live in the evacuation center with caring about many things. Before the earthquake, " $D$ " had his own business, so, because of the lack of facilities and equipment, he could not do any work, even though he wanted to.

However, some people in neighborhood told them that he must be living a wealthy life because he was receiving substantial compensation from the government. Actually, it was difficult having to worry about what others thought about them, so they took special care selecting what to eat and wear. The common topics they discussed were environmental hardships in the evacuation center right after the earthquake, and issues regarding compensation from the government and communication problems with the neighborhood. The speech and behavior of others in relation to compensation inflicted emotional pain on them. They care about someone's eyes in anytime, so they were terribly worried about a number of issues that could not be solved with money. The amount of compensation had not yet been decided, but the estimates were low. As for 


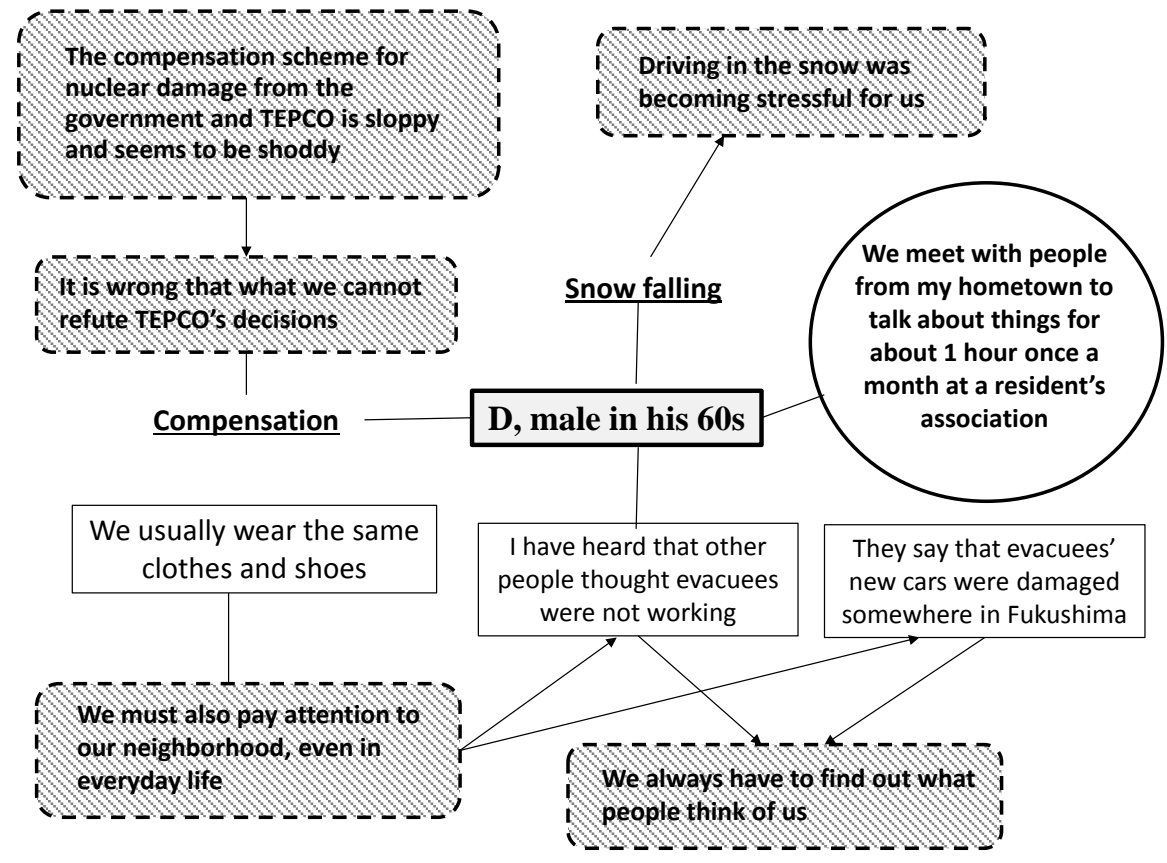

Figure 4. Story on Participant D. ${ }^{*}$ Circle with solid line presents positive thing on participant. Square presents stories participants described. Shaded square with dot line presents participant's emotion.

communication with their former neighborhood, he asked one member of "Tonarigumi", a community group that formed to plan a festival known as "Aoi matsuri", to babysit. Although they had previously lived in a close-knit community, the evacuation brought about poor communication and made it difficult to develop new relationships. In addition, issues surrounding compensation caused even more stress for the evacuees.

\section{Discussions}

The present study analyzed stress coping and psychological conditions 4 years after an earthquake and nuclear disaster among long-term evacuees who had been residents of Fukushima. All participants had been forced to take emergency shelter at great inconvenience in their early evacuation as shown in the previous research [9], and then they are continuing to have stressful experiences.

The results of TAE-24 showed that some stress coping scores were significantly higher in males than in females. However, cluster scores in females were higher than those in males from a previous study [10]. In addition, stress levels were higher in females than in males in a previous study regarding the Great Hanshin earthquake, so females were considered to be more stressful in general. Unlike typical disasters, many patients show depressive symptoms after a nuclear accident [11]. In Fukushima, this was also the case because of long-term evacuations, moving to temporary accommodations many times, and having no prospects for restorations [12]. Farmers and fishermen lost their jobs after the disaster, suggesting that men experienced high levels of stress because they had 
lost their motivation in life.

" $A$ " had a higher "catharsis" score than the other participants, and she described in her interview that people such as family, friends, and neighbors were important to her. In general, women are more predisposed than men to expressing themselves through language, and they have a high propensity for requesting an emotional crutch and specific types of support [13]. Thus, women were more capable of relieving stress through catharsis than men. Family members, communication with the neighborhood, and cooperative frameworks were important for long-term evacuees. Men seem to have more complains about their lives, and thus showed lower catharsis. B's score was higher than a normal adult male's score. "B" showed a higher score for "Avoidance-like thinking" and "Giving up" compared with other stress coping factors. If the nuclear power plant or evacuation center was seen as the root cause of the problem, it was difficult to solve, so "Avoidance-like thinking" and "Giving up" were significantly higher. "B" tried to solve problems by setting up a self-help group. It seems that indirect coping styles are better suited for solving long-term problems. Some participants described that they had to give up on communication with the neighborhood after the evacuation. They experienced several times that they could not do anything by themselves and made little headway, so they showed higher "Giving up" scores. In addition, "Plan drafting" scores in three of the participants might have been slightly higher than normal adult scores since all participants were self-employed business owners before the earthquake. Problems associated with compensation and the neighborhood were listed as the current issues from these participants. Disaster victims had to do many nerve-racking things as their neighborhoods broke up and their community was restructured soon after the earthquake, so they needed to maintain close relationships and communication for a long time without commiseration or pity. Therefore, it was difficult to satisfy their demands through short-term support and interaction [14]. Many issues remain, such as how to recover the homes and valuables destroyed by the tsunami and how to dispose of things contaminated with radioactive material, so residents who lived around the nuclear power plant in Fukushima have still not returned to their homes. Therefore, it is important to provide support for evacuees so that original residents can better understand their situation.

This study did have several limitations, in that the sample was small and consisted of only self-employed business owners before the earthquake. Therefore, the findings are generalizable only to those evacuees who had their own business in $\mathrm{Q}$ area. However, it is important to note that the objective of the study was to examine stress coping among and problems faced by long-term evacuees. Thus, we recommend that future research on stress coping should focus on younger evacuees and those who refused to return to their hometown for comparison with the findings of the present study.

\section{Conclusion}

This study seeks to contribute to the understanding of how evacuees from Q 
area experienced stressful conditions through conflicts in relation to neighborhood communication and compensation from TEPCO and the Japanese government. Nearly 7 years have passed since the Great East Japan earthquake, but the reconstruction and revitalization of Fukushima is still delayed. However, during this time, evacuees have been forced to live in temporary housing away from their hometowns, while holding on to hope that they can return in the future. Evacuees must construct new communities in new settings, and this cannot be achieved overnight. Therefore, these evacuees hope that the original residents can better understand them and their problems.

\section{Acknowledgements}

Funding for this study was provided by the Ministry of the Environment, Government of Japan. We thank all the people who provided valuable contributions to this research. We are grateful to Prof. Osanai for helpful comments. We also thank the anonymous reviewers for their constructive suggestions on earlier versions of this article.

\section{References}

[1] Yamamoto, A. (2011) Experiences of the Great East Japan Earthquake March 2011. International Nursing Review, 58, 332-334. https://doi.org/10.1111/j.1466-7657.2011.00924.x

[2] Fire and Disaster Management Agency Information 2017. http://www.fdma.go.jp/bn/higaihou/pdf/jishin/156.pdf

[3] Steps for Revitalization in Fukushima November 20, 2017. Fukushima Revitalization Station.

https://www.pref.fukushima.lg.jp/uploaded/attachment/250520.pdf

[4] Q Town HP. Namie Revitalization Report. http://www.town.namie.fukushima.jp/uploaded/attachment/7963.pdf

[5] Q Town HP Number of Evacuees. http://www.town.namie.fukushima.jp/site/shinsai/17592.html

[6] Masuda, K., Tsujiuchi, T., Yamaguchi, M., et al. (2013) Genshiryoku HatsudenshoJikoniyoru Kengai Hinannitomonau Kinrin Kankei no Kihakuka. Journal of Health and Welfare Statistics, 60, 9-16. http://www.hws-kyokai.or.jp/images/ronbun/all/201308-02.pdf

[7] Kamimura, E., Ebihara, Y., Sato, K., Togasaki, T. and Sakano, Y. (1995) A Validation of Three-Dimensional Model of Coping Response and the Development of Tri-Axial Coping Scale (TAC-24). Bulletin of Counseling and School Psychology, 31, 41-47.

[8] HoNakamura, N. and Agari, I.(2004) Coping with Daily Hassles and Stress Responses in Middle-Aged and Elderly Japanese. The Japanese Journal of Health Psychology, 17, 18-28. https://doi.org/10.11560/jahp.17.1_18

[9] Noto, Y., Kitamiya, C., Itaki, C., Urushizaka, M., Kidachi, R. and Yamabe, H. (2013) Role of Nurses in a Nuclear Disaster: Experience in the Fukushima Daiichi Nuclear Powerplant Accident. International Nursing Review, 60, 196-200.

https://doi.org/10.1111/inr.12014

[10] Joh, H. and Obana, N. (1995) Some Aspects of Disaster Stress under the Great 
Hanshin Earth Quake. The Japanese Journal of Experimental Social Psychology, 35, 232-242. https://doi.org/10.2130/jjesp.35.232

[11] Kukihara, H., Uchiyama, K. and Horikawa, E. (2015) Nihon niokeruJishin, Tsunami, Genpatsu jikoHisaishano Trauma, Yokuutu, Resilience. Psychiatria et neurologia Japonica, 117, 957-964.

[12] Naiki, M., Morita, M. and Takada, S. (2015) The Health and Daily Lives of Residents in Government-Subsidized Housing in the Phase of Recovery from a Nuclear Disaster-A Survey of Residents Compulsorily Evacuated from B Town after the Fukushima Daiichi Nuclear Power Plant Accident. Journal of Japan Society of Disaster Nursing, 17, 34-44.

[13] Shimazu, A. (2005) Sex Differences in Stress Coping. Gender \& Sex Specific Medicine, 2, 31-35.

[14] Sasaki, S. (2013) 3 11Higashinihon-Daishinsai no Omoi to Genjitu. Bulletin of the Northern Regions Academic Information Center, Hokusho University, 5, 73-78. 